\title{
The dynamic model of managing the rating of a Russian Federation entity
}

\author{
Artur Mitsel $^{1,2,3}$, Anna German ${ }^{1}$ \\ ${ }^{1}$ Higher Mathematics and Mathematical Physics \\ Department, \\ ${ }^{2}$ Information Systems Department Yurga Institute of \\ Technology \\ ${ }^{1,2}$ National Research Tomsk Polytechnic University, \\ ${ }^{3}$ Automated Control Systems Department \\ Tomsk State University of Control Systems and \\ Radioelectronics \\ Tomsk, Russia \\ maa@asu.tusur.ru
}

\begin{abstract}
The article presents the dynamic model of rating management. To build a management model, a rating assessment model must be previously built. We have constructed a regression model of rating evaluation which includes eight key indices that affect the rating level. On the basis of this model, a dynamic model of rating management for the Russian Federation entities has been formed. The model has been tested on the Tomsk Region rating. The article is of potential use for the Russian Federation entity authorities that may use it to assess the expected level.
\end{abstract}

Keywords-credit ratings; Russian Federation entities; managing the risk for the probability of default.

Getting a credit rating is a most common way to increase investment attractiveness for corporate and government bonds. The credit rating of the region is an integrated assessment that shows the ability of the regional governmental authority to completely and timely discharge bonds, i.e. repay and service loans, taking into account the forecast of changes in the socio-political situation and economic environment. Credit ratings reflect the opinion of agency analysts on the solvency of a Russian Federation constituent entity at the time of assigning a rating status.

The credit rating is calculated by rating agencies based on the present and past financial history. These agencies may be either regional (sectoral), which implies specializing in a particular geographic region (industry), or international, including Standard \& Poor's, Moody's Investors Service, Fitch Ratings, etc.

The subject of rating in the general sense, i.e. the definition of company / bank, etc. rating is well-developed. For example, in the field of corporate rating analysis, Young-Chan Lee applied the support vector method (SVM) for the problem of determining the corporate credit rating in an attempt to propose a new model with a better interpretation. Here, the grid search method with a 5-fold test is used to determine the optimal values of the function parameters [1].

\author{
Marina Grigoryeva \\ Automated Control Systems Department \\ Tomsk State University of Control Systems and \\ Radioelectronics, \\ Information Systems Department Yurga Institute of \\ Technology \\ National research Tomsk Polytechnic University \\ Tomsk, Russia \\ marina241063@mail.ru
}

Chen and Chiou introduce the use of a fuzzy creditrating approach for credit ratings of commercial loans, in which evaluation criteria are modeled as a hierarchical decision-making structure. The method for proving synthesis, namely the fuzzy integral, is then used to combine credit information in the ascending path [2].

Melliosa and Paget-Blancb have studied the factors determining the sovereign credit ratings provided by three major rating agencies: Fitch Ratings, Moody's and Standard and Poor's. The analysis of the main components is implemented to identify common factors affecting these ratings. The variables correlate with these factors, and then are evaluated through an ordered logistic model. The results indicate that sovereign ratings are mainly affected by: income per capita, state revenues, real exchange rate changes, and inflation rates [3].

Pogue and Soldofsky's classic question states: "What's in a bond rating?". The authors acknowledge that ratings are partly dependent on readily available statistics on a firm's performance and financial condition. Examples of such statistics are profit coverage, liquidity ratios and rates of return [4].

A number of scholars argue that successful modeling of ratings is possible when using the model of ordered selection and simple methods of linear regression.

For instance, referring to a sovereign rating, Cantor and Packer selected six factors out of a large multitude of criteria used by the two leading rating agencies S \& $\mathrm{P}$ and Moody's that they believe are important in determining the credit rating: income per capita, GDP growth rates, inflation, external debt, level of economic development and history as a default [5].

Kramin et al. [6] devoted their article Drivers of economic growth and investment attractiveness of Russian regions to the identification and substantiation of growth drivers and regional development in Russia. On the basis of regression analysis, the paper examined the influence of the domestic demand level and income inequality in the regions 
of Russia on the rates of their economic growth and investment attractiveness.

Bennella et al. [7] explore the modeling and training in neural networks and the model of ordered selection for a large sample of ratings provided by rating agencies. They assume that the model of ordered selection may account the discreteness of the dependent variable nature, and therefore be the most suitable econometric rating methodology.

Linden, McNamara, and Vaaler used a multilevel ordinal logistic regression to analyze rating assessment. They investigated six rating agencies and determined systematic differences in the ratings of these agencies [8].

This again confirms the impossibility of creating a unified model for credit rating management due to differences in the direct objectives of credit rating determination [8].

Huang et al. [9] proposed a relatively new method of machine learning to solve the problem of providing a model with better interpretation. They used back propagation of a neural network.

In [10], the model for determining the credit rating was developed based on the regression model.

To build this model, such indices that affect the credit rating value were chosen:

- $\mathrm{x} 1$ = Direct debt / Income excluding gratuitous receipts;

- x2 = Conditional debt / Income excluding gratuitous receipts;

- $\mathrm{x} 3$ = Income discounting gratuitous receipts / Total revenue;

- $\mathrm{x} 4$ = Budget deficit / Income excluding gratuitous receipts;

- $\mathrm{x} 5$ = Debt service / Income excluding gratuitous receipts;

- x6 = Total public debt / Gross regional product;

- $\mathrm{x} 7$ = General government debt expenditure / Budget expenditure;

- $\mathrm{x} 8$ = Borrowed funds / Total budget revenue;

- $\mathrm{x} 9$ = Industrial production index / Gross domestic product of the Russian Federation.

The index values were calculated for 33 regions involved in the structuring [12-14].

The conducted factor analysis showed that to simplify the model it is possible to exclude one factor, namely: Borrowed funds / Total budget revenue. Based on the factor analysis results, the following were re-identified:

- $\mathrm{x} 1=$ Direct debt / Income excluding gratuitous receipts;

- x2 = Conditional debt / Income excluding gratuitous receipts;
- $\mathrm{x} 3$ = Income excluding gratuitous receipts / Total revenue;

- $\mathrm{x} 4$ = Budget deficit / Income excluding gratuitous receipts;

- $\mathrm{x} 5$ = Debt service / Income excluding gratuitous receipts;

- x6 = Total public debt / Gross regional product;

- $\mathrm{x} 7$ = General government debt expenditure / Budget expenditure;

- $\mathrm{x} 8$ = Industrial production index / Gross domestic product of the Russian Federation.

Using the identified indices taken as $\mathrm{X}$, and the value for the probability of default taken as $\mathrm{Y}$, a nonlinear regression model was formed. The following equation was chosen for the regression model:

$$
\begin{aligned}
& y=k_{1}+\left(x_{1}+x_{2}\right) \cdot k_{2}+x_{3}^{2} \cdot k_{3}+x_{4}^{3} \cdot k_{4}+ \\
& +\left(x_{5}+x_{7}\right) \cdot k_{5}+x_{6} \cdot k_{6}+x_{8} \cdot k_{7}
\end{aligned}
$$

Coefficients $k_{i}, i=\overline{1,7}$ acquired the following values:

$$
\begin{aligned}
& k_{1}=4,17, k_{2}=-6,05, k_{3}=-1.71, k_{4}=30,39, \\
& k_{5}=27,34, k_{6}=0,03, k_{7}=6,6 .
\end{aligned}
$$

In this paper, the rating management model was developed by the model [10].

\section{EXPERIMENTAL PART}

\section{A. The dynamic model of regional rating management without feedback factors}

We have identified 8 indices most critical for assessing the risk of refinancing that affect the rating of the entity [10, 15]. Let the values of these indices exceed the permissible limits and we want to change their values in order to avoid a low rating. Thus, we need changes in the key indices [16].

Let us take $x_{i}(t), i=1, \ldots, n$ for the indices at the time moment $t, t=1, \ldots, T-1$, where $T$ - planned moment of time for the region to reach the required rating level; $x_{i}^{0}(t)$ - planned values of indices that correspond to the sustainable functioning of the region; $V(t)$ - probability of default, which the region has in the state of 'crisis'; $V^{0}(t)-$ maximum permissible probability of default, at which the region's stable state is provided.

The following expression was obtained for the probability of default in [11]:

$$
\begin{aligned}
& V(t)=\left(x_{1}(t)+x_{2}(t)\right) \cdot k_{1}+x_{3}^{2}(t) \cdot k_{2}+ \\
& +x_{4}^{3}(t) \cdot k_{3}+\left(x_{5}(t)+x_{7}(t)\right) \cdot k_{4}+ \\
& +x_{6}(t) \cdot k_{5}+x_{8}(t) \cdot k_{6}
\end{aligned}
$$


where $x_{i}(t)$ - indices of financial, as well as social and political activity of the region. The values of $k_{i}, i=\overline{1,6}$ factors thus equal:

$$
\begin{aligned}
& k_{1}=19,12, \quad k_{2}=22,07, k_{3}=0,84, \\
& k_{4}=4,58, k_{5}=21,61, k_{6}=-26,89 .
\end{aligned}
$$

Let us rename the indices and factors of the model (1):

$$
\begin{gathered}
y_{i}(t)=x_{i}(t), i=1,2,5,6,7,8 ; \\
y_{3}=x_{3}^{2}(t), y_{4}=x_{4}^{3}(t) . \\
k 1_{1}=k_{1} ; k 1_{2}=k_{1} ; k 1_{3}=k_{2} ; k 1_{4}=k_{3} ; \\
k 1_{5}=k_{4} ; k 1_{6}=k_{5} ; k 1_{7}=k_{4} ; k 1_{8}=k_{6} .
\end{gathered}
$$

Then correspondence (1) takes the form of:

$$
V(t)=\sum_{i=1}^{n} V_{i}(t), n=8
$$

where $V_{i}(t)=k 1_{i} y_{i}-$ the probability of default conditioned by the $i$ index.

The dependence of $x_{i}(t)$ indices on time can be presented as:

$$
x_{i}(t+1)=\left(1+\mu_{i}^{\$}(t)\right) \cdot x_{i}(t)
$$

where $\mu_{i}^{\$}(t)$ - the rate of change in the $i$ index.

The dynamics for the probability of default is given as follows:

$$
V_{i}(t+1)=\left(1+\mu_{i}(t)\right)\left(V_{i}(t)+u_{i}(t)\right), i=1, \ldots, 8,
$$

where

$$
\begin{aligned}
& \mu_{i}=\mu_{i}^{\$}, i=1,2,5,6,7,8 ; \\
& \mu_{3}=\left(1+\mu_{3}^{\$}\right)^{2}-1, \mu_{4}=\left(1+\mu_{4}^{\$}\right)^{3}-1 .
\end{aligned}
$$

Here $u_{i}$ - management associated with the change of the $i$ index.

The dependence of the maximum permissible probability of default (the reference probability) on time can be expressed as:

$$
V^{0}(t+1)=\left(1-\mu_{0}\right) V^{0}(t)
$$

where $\mu_{0}-$ desired rate of change in the probability of default.

Let us introduce the vector

$$
z(t)=\left(V_{1}(t), V_{2}(t), \ldots, V_{n}(t), V^{0}(t)\right)^{T}
$$
of:

Then equations (6) and (8) may be rewritten in the form

$$
z(t+1)=A_{0}(t) z(t)+B_{0}(t) u(t)
$$

where $A_{0}(t)$-diagonal matrix of $(n+1) \times(n+1)$ dimension

$$
A_{0}(t)=\operatorname{diag}\left(1+\mu_{1}(t),, 1+\mu_{n}(t), 1-\mu_{0}(t)\right) ;
$$

$B_{0}(t)$ - diagonal matrix of $\left.(n+1) \times n\right)$ dimension

$$
B_{0}(t)=\left(\begin{array}{ccc}
1+\mu_{1}(t) & \ldots & 0 \\
\ldots & \ldots & 0 \\
0 & \ldots & 1+\mu_{n}(t) \\
0 & \ldots & 0
\end{array}\right)
$$

As the objective function, let us choose a quadratic functional of:

$$
\begin{aligned}
& J=\sum_{t=0}^{T-1}\left[\left[V(t)-V^{0}(t)\right]^{2}+(u(t))^{T} R u(t)\right]+ \\
& +\left[V(T)-V^{0}(t)\right]^{2},
\end{aligned}
$$

which characterizes the quality of tracking planned probability of a regional default. By minimizing this functionality, we thereby ensure the region's correspondence to the planned probability. Here $R(t)-$ diagonal matrix of weight factors for $n \times n$ dimension.

We will introduce $z(t)$ vector in (10). The value $\left(V(t)-V^{0}(t)\right)$ will take the form of $\left(V(t)-V^{0}(t)\right)=C z(t)$, where

$C=(1,1, \ldots, 1,-1) \in R^{n+1} \quad$ The quality criterion $J$ will take the form of:

$$
\begin{aligned}
& J=\sum_{t=1}^{T-1} z^{T}(t) C^{T} C z(t)+\sum_{t=0}^{T-1}\left(u^{T}(t) R u(t)\right)+ \\
& +z^{T}(T) C^{T} C z(T) \rightarrow \min _{u(t)}
\end{aligned}
$$

Thus, we have the problem of optimal management, in which the equation of state is described by the multi-step process (8), and the quality functional - by the expression (110. The management is specified by $u(t)$ vector.

An optimal solution for $(\bar{z}(t), \bar{u}(t))$ must be found where the functional (11) assumes a minimum value.

\section{B. Problem solution}

We have the problem of optimal management with a quadratic criterion.

We transform our problem to an equivalent problem of absolute minimization of a multivariable function. As a result, we will get:

$$
J=\left\{\begin{array}{l}
z^{T}(0) L_{11}(0) z(0)+ \\
\left(2 z^{T}(0) \phi-B\right)^{T} U+U^{T} S U
\end{array}\right\} \rightarrow \min _{U},
$$


where

$$
\begin{aligned}
& \left\{\begin{array}{l}
L_{11}(t)=\sum_{j=0}^{n} A_{j}^{T}(t) Q(t+1) A_{j}(t), \\
L_{22}(t)=\sum_{j=0}^{n} B_{j}^{T}(t) Q(t+1) B_{j}(t), t=T-1, T-2, \ldots, 0 . \\
L_{12}(t)=\sum_{j=0}^{n} A_{j}^{T}(t) Q(t+1) B_{j}(t) .
\end{array}\right. \\
& Q(T)=h, h=C^{T} C \text {; } \\
& Q(t)=L_{11}(t)+h, t=T-1, T-2, \ldots, 0 . \\
& \phi_{s}=\left\{\prod_{j=0}^{s-1} A_{0}(j)\right\} L_{12}(s) ; s=0,1, \ldots, T-1, \\
& \phi_{0}=L_{12}(0) \text {. }
\end{aligned}
$$$$
S_{s i}=S_{i s}=\left\{\begin{array}{l}
B_{0}(i)\left(\prod_{j=i}^{s-1} A_{0}(j)\right) L_{12}(s), i<s ; \\
i, s=0,1, \ldots, T-1 ; \\
L_{22}(i)+R(i), i=s ;
\end{array}\right.
$$$$
\prod_{j=p}^{p-1} A_{0}(j)=I
$$$$
\phi=\left(\begin{array}{llll}
\phi_{0} & \phi_{1} & \ldots & \phi_{T-1}
\end{array}\right) ;
$$$$
B=\left(\begin{array}{llll}
b(0) & b(1) & \ldots & b(T-1)
\end{array}\right)^{T} ;
$$$$
U=\left(\begin{array}{llll}
u(0) & u(1) & \ldots & u(T-1)
\end{array}\right)^{T} .
$$

Problem solution is determined by the formula:

$$
U=-S^{-1} \phi^{T} z(0)
$$

In accordance with the obtained management, we find $z(t)$ variables by formula (9), and then calculate the index values:

$$
\begin{aligned}
& x_{i}(t)=z_{i}(t) / k 1_{i}, i=1,2,5,6,7,8 \\
& x_{3}(t)=\sqrt{z_{3}(t) / k 1_{3}}, \quad x_{4}(t)=\left(z_{4}(t) / k 1_{4}\right)^{1 / 3} .
\end{aligned}
$$

\section{Simulation results}

The developed model was applied to the rating of the Tomsk Region. As $x_{i}(t), i=1, \ldots, n$, index values of the period from 01 April,.2008 to 01 January 2015 were taken that prove most critical for assessing refinancing risks and affect the entity rating.

Since the Tomsk Region rating was assigned only in 2013, real indices were taken for each quarter, starting from 2014. With the formed regression model, the estimated rating level for the missing periods was calculated. It was determined that for the first moment of time the estimated probability of default corresponded to the $\mathrm{B}+$ rating $(10.43 \%)$ [14,18-19].

As a maximum-permissible probability for the first moment of time, a value corresponding to the $\mathrm{BB}$ rating $(5.75 \%)$ was set. In the course of time, this value also had negative dynamics.

Factors $\mathbb{\mu}_{i}$ were calculated with the following formula:

$$
\begin{aligned}
& \mathbb{R}_{i}^{\mathbf{S}}=\frac{\sum_{t=2}^{n}\left(x_{i}(t) x_{i}(t-1)\right)}{\sum_{t=2}^{n}\left(x_{i}(t-1)\right)^{2}}-1, n=28, \\
& i=1, \ldots, 6 .
\end{aligned}
$$

The graphs of the maximum permissible and real probability of default are presented in Fig. 1.

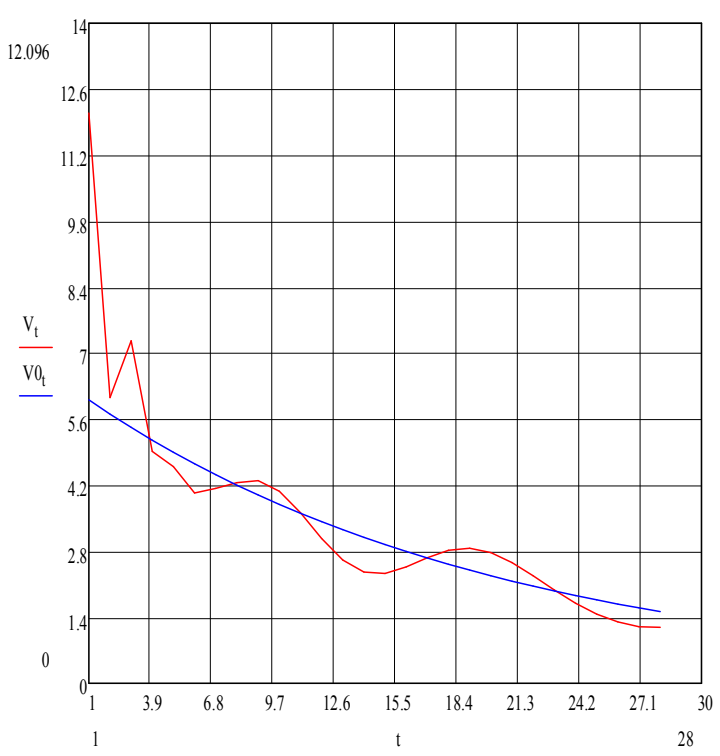

Fig.1. Maximum permissible $V 0_{t}$ and real $V_{t}$ probability of default for quarter ( $(\mathrm{t})$

It can be observed from the graphs that over time real probability displays a tendency toward maximum permissible probability.

The values of indices that provide sustainable development of the region are shown in Fig. 2 


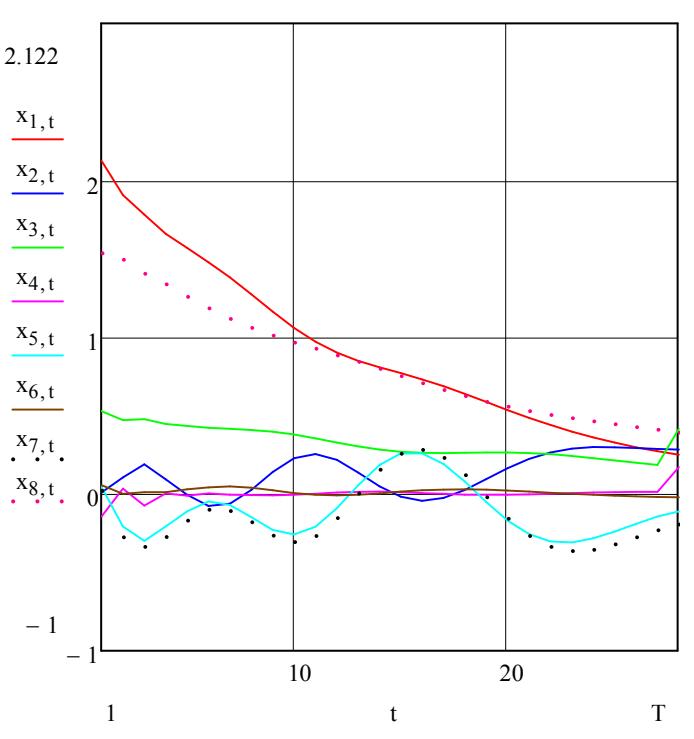

Fig. 2. Optimal values of indices for which the probability of default assumes maximum permissible values for quarter $(t)$

The analysis of calculations has shown that to obtain the maximum necessary probability for a given period, it is necessary to consistently decrease the following the first, third, and eighth indices (i.e. the correspondence of direct debt to one's own revenues, the share of one's own revenues in budget revenues, the ratio of borrowed funds to income). Since the problem of optimal management was solved without restrictions on permissible values of the second, fourth, fifth, sixth and seventh indices (i.e. the ratio of the conditional debt to one's own revenues, the ratio of the budget deficit to one's own revenues, the ratio of debt servicing to one's own revenues, general government debt to gross regional product, expenditures on general government debt to budget expenditures), the indices entered the negative value range.

\section{DISCUSSIONS}

In this paper, a dynamic model of a region's credit rating management was built. The model was based on the quadratic quality criteria and linear control law, and was tested on real data for the Tomsk Region. As a result, an optimal management for the given probability of default was obtained, namely the values of indices that provide reaching the maximum permissible probability of $1.5 \%$, which corresponds to the BBB- rating at the final time moment $T$. Herewith, the optimal level of indices may be reached by changing only one of the constituents, i.e. increasing one's own budget revenues. This is because in all indices that must be reduced (the correspondence of direct debt to one's own revenues, the share of one's own revenues in budget revenues, the ratio of borrowings to income), an increase in one's own revenues will lead to an increase in the denominator, thus decreasing the index itself.

\section{REFERENCES}

[1] Application of support vector machines to corporate credit rating prediction. Expert Systems with Applications, vol. 33 (1), July 2007, pp. 67-74
[2] A fuzzy credit-rating approach for commercial loans: a Taiwan case. Omega, vol. 27 (4), August 1999, pp. 407-419

[3] Which factors to determine the sovereign credit ratings? The European Journal of Finance, vol. 12 (4), 2006

[4] Thomas F. Pogue and Robert M. Soldofsky. What's in a Bond Rating? Journal of Financial and Quantitative Analysis, vol. 4 (2), June 1969, pp. 201-228

[5] R. Cantor, F. Packer. Federal Reserve Bank of New York Economic Policy Review, 2 (1996)

[6] Kramin M.V., Safiullin L.N., Kramin T.V., Timiryasova A.V., Life Science Journal, vol. 11 (6) (Supplement 1106s), June 25, 2014.

[7] J. A. Bennella, D. Crabbea, S. Thomasa, O. ap Gwilymb. Modelling sovereign credit ratings: Neural networks versus ordered profit. Expert Systems with Applications, vol. 30 (3), April 2006, pp. 415425

[8] Linden, F., McNamara, G., \& Vaaler, P. Idiosyncratic region and rater effects on sovereign credit ratings, presented at the international management meeting in San Diego, California, USA, August 1998.

[9] Zan Huang, Hsinchun Chena, Chia-Jung Hsua, Wun-Hwa Chenb, Soushhan Wuc. Credit rating analysis with support vector machines and neural networks: a market comparative study. Vol. 37 (4), September 2004, pp. 543-558

[10] Mycel A. A., German A.V. A mathematical model for assessing the credit rating of the regions of the Russian Federation / / Economic Analysis: Theory of Practice, 2015, no. 6 (405), pp. 2-8.

[11] Ministry of Finance of the Russian Federation: Public debt [Electronic resource]. Access mode: http://www.minfin.ru/en/perfomance/public_debt/subdbt/, free.

[12] Federal Service of State Statistics [Electronic resource]. Access mode: http://www.gks.ru/, free.

[13] Federal Treasury: Budgets of the Subjects of the Russian Federation [Electronic resource]. Access mode: http://www.roskazna.ru/byudzhetov-subektov-rf-i-mestnykhbyudzhetov/, free.

[14] Fisher R.A. Statistical Methods for Research Workers. 14th ed. Edinburgh: Oliver and Boyd, 1970, p. 102.

[15] Tonu Kollo. Multivariate Statistics: Theory and Applications: Proceedings of IX, p. 131.

[16] Kenney, J. F. and Keeping, E. S. Linear Regression, Simple Correlation, and Contingency. Princeton, 1997. pp. 199-237.

[17] Default Study and Rating Transitions [Electronic resource]. London: Standard \& Poor's, 2010, URL: http://www.standardandpoors.com/ratings/articles/er/us/?assetID=124 5207201119 (date of access: 13.04.16)

[18] Historical Default Rates of Corporate Bonds Issuers, 1920-1999 [Electronic resource]. S. Keenan, D. Hamilton, A. Berthault. London: Moody's investors service, 2010, URL: http://www.moodyskmv.com/research/whitepaper/52453.pdf (date of access: 13.04.16)

[19] Verde, N. Fitch Ratings Global Corporate Finance 2009 Transition and Default Study. 2010, URL: http://www.levow.com/SGdownlood/\%20Debt\%20Capital\%20Market s/Fitch\%20Ratings\%20Corporate\%20Transition\%20Study\%202009.p df (date of access: 13.04.16) 